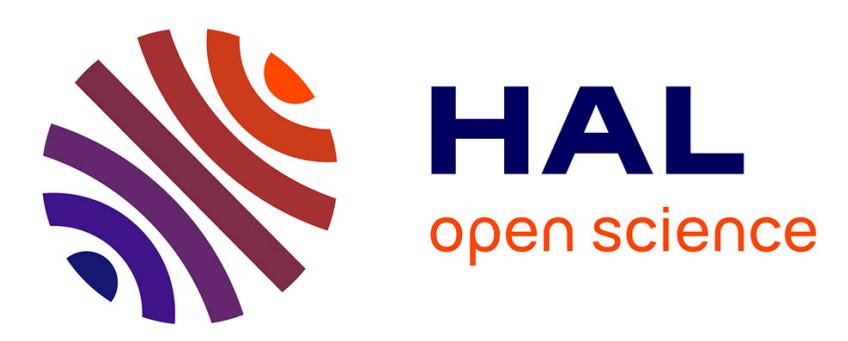

\title{
Experimental measurements and numerical modelling of the mechanical behaviour of a glass plain weave composite reinforcement
}

\author{
Mehdi Ghazimoradi, Valter Carvelli, Naïm Naouar, Philippe Boisse
}

\section{- To cite this version:}

Mehdi Ghazimoradi, Valter Carvelli, Naïm Naouar, Philippe Boisse. Experimental measurements and numerical modelling of the mechanical behaviour of a glass plain weave composite reinforcement. Journal of Reinforced Plastics and Composites, 2020, 39 (1-2), pp.45-59. 10.1177/0731684419868846 . hal-02288991

\section{HAL Id: hal-02288991 \\ https://hal.science/hal-02288991}

Submitted on 17 Dec 2020

HAL is a multi-disciplinary open access archive for the deposit and dissemination of scientific research documents, whether they are published or not. The documents may come from teaching and research institutions in France or abroad, or from public or private research centers.
L'archive ouverte pluridisciplinaire HAL, est destinée au dépôt et à la diffusion de documents scientifiques de niveau recherche, publiés ou non, émanant des établissements d'enseignement et de recherche français ou étrangers, des laboratoires publics ou privés. 


\title{
Experimental measurements and numerical modelling of the mechanical behaviour of a glass plain weave composite reinforcement
}

\author{
Mehdi Ghazimoradi , Valter Carvelli, Naim Naouar ${ }^{3}$ and Philippe Boisse $^{3}$
}

\author{
${ }^{1}$ Department of Mechanical and Mechatronics Engineering, University of Waterloo, Waterloo, Canada \\ ${ }^{2}$ Department A.B.C., Politecnico di Milano, Milan, Italy \\ ${ }^{3}$ LaMCoS UMR 5259, INSA-Lyon, Université de Lyon, Villeurbanne, France \\ Corresponding author: \\ Valter Carvelli, Politecnico di Milano, Piazza Leonardo Da Vinci, 32Milano, 20133, Italy. \\ Email: valter.carvelli@polimi.it
}

\begin{abstract}
The study deals with the mechanical behaviour of a glass plain weave composite reinforcement. The experimental activities were focused mainly on uniaxial and biaxial extension tests. Besides, in-plane shear deformation was measured by bias extension test, and for the sake of completeness out-of-plane bending behaviour. In the numerical study, a hyperelastic constitutive model for the yarn material was adopted and validated for the meso scale prediction of the mechanical behaviour of the glass plain weave reinforcement. The model was validated for biaxial tensile and in-plane shear deformation.
\end{abstract}

\section{Keywords}

Composite reinforcement, glass, plain weave textile, experimental measurements, hyperelastic numerical model

\section{Introduction}

The mechanical behaviour of textile reinforcements for composite materials is difficult to predict due to the complex interactions of yarns in the textile and of fibres in each yarn. Indeed, the multi-scale characterization is also a considerable obstacle for a complete understanding of the mechanical behaviour of textile composite reinforcements.

While the traditional short-fibre and unidirectional long fibre composites are often investigated at microand macro-scales ${ }^{1}$, textile composites and specifically woven composite reinforcements have an additional intermediate level, known as meso-scale. Essentially, woven fabrics can be considered as structured, hierarchical materials, having three structural levels ${ }^{2-4}$, namely: macro, meso and micro (see Figure 1). The micro and meso features are of relevant importance for the macro mechanical properties of a woven reinforcement. They affect the deformation mode during the complex shape forming process of a woven reinforcement in the initial step of the composite manufacturing, generally obtained by liquid moulding. In-plane and out-of-plane deformations imparted during forming have considerable influence on the mechanical properties of the final composite component.

One of the most important deformation modes of woven composite reinforcement during forming is the in-plane shear, and the number of researches ${ }^{5-11}$ dedicated to the topic in last two decades highlights the importance for the textile composite manufacturing. In the 60s, Lindberg et al., ${ }^{1-12}$ Grosberg et al. ${ }^{13,14}$ and Spivak et al. ${ }^{15}$ started the study of the in-plane shear behaviour of technical textiles. Spivak et al. ${ }^{15}$ proposed a simple experimental method called "Bias extension test" to analyse the shear deformation. After that, Wang et al. ${ }^{16}$ demonstrated the distribution of the different shear zones during bias extension test. 
(a)

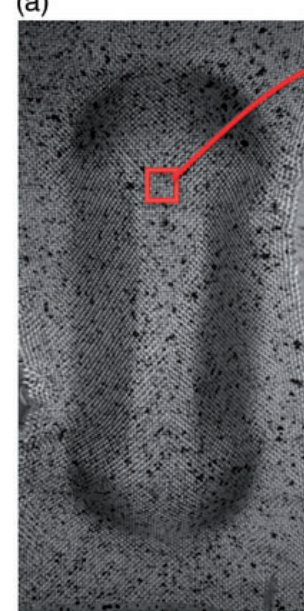

(b)

(c)

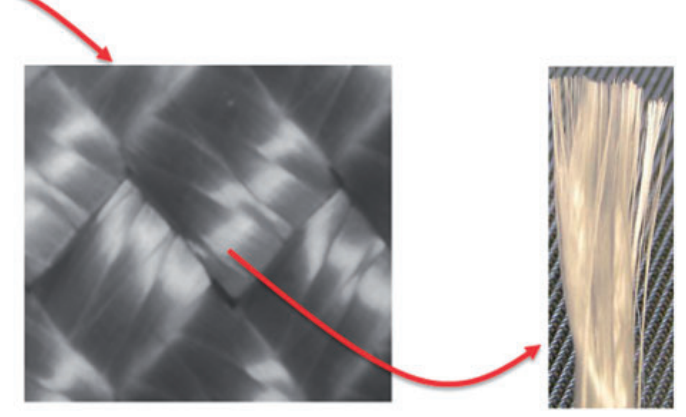

Figure I. Different scale of a woven textile reinforcement: (a) macro; (b) meso; (c) micro.

Besides, recently Alsayednoor et al. ${ }^{17}$ developed the modelling and characterisation of technical textiles during uniaxial bias extension test.

However, the shear deformability of a woven reinforcement is connected to specific deformation modes of the yarn, related to fibres interactions at the microscale, and to the interaction of the yarns, related to the interlacement at the meso-scale.

Therefore, improving the knowledge on the mechanical behaviour of fibrous textile materials, from the micro and meso scale, is an important research field to develop accurate theoretical models, predictive methods, and experimental approaches. ${ }^{18-22}$

Accurate predictive tools are highly on demand for the simulation and the prediction of the mechanical behaviour of textile reinforcements during complex loading condition as in the forming phase. It decreases the cost of manufacturing trail, and help to avoid operational defects.

In this context, the present study adopted a hyperelastic constitutive model $^{23}$ to numerically predict the macro mechanical properties of a glass plain weave composite reinforcement. The supposed period interlacement allowed to focus the modelling at the mesoscale, by studying the representative volume element (RVE) of the textile. The specific deformation modes of the yarn were considered in the constitutive model, detailing the strain energy function associated to each deformation mode, while an accurate threedimensional description of the interlacement at the meso-scale allowed to detect the effect of the interaction of the yarns on the macro mechanical behaviour of the woven reinforcement.

Beside the numerical modelling, an extensive experimental characterization was performed to provide the input parameters of the material model of the yarns, and to measure the mechanical response of the woven reinforcement for different in-plane loading conditions. The latter were considered to assess the accuracy of the numerical model.

The aims of this study were: (i) to experimentally measure some mechanical properties of the yarns and the textile reinforcement; (ii) to predict the nonlinear behaviour of the glass plain weave reinforcement for any in-plane loading conditions; (iii) to compare the meso-scale finite element (FE) modelling results to the experimental observations of biaxial tensile and in-plane shear loadings. Hence, the paper is structured as: an initial description of the considered glass textile reinforcement; an overview of the experimental methods and devices; description of the hyperelastic constitutive model adopted for the yarns; details of the explicit FE analyses; identification of the model parameters; finally, comparison of the numerical results and the experimental measurements.

\section{Materials and experimental methods}

The fabric considered in the investigation is a glass plain weave composite reinforcement produced by "Gavazzi Tessuti Tecnici", Italy. The fibre material is EC9 glass. Some features of the fibrous textile are listed in Table 1, according to the producer datasheet. Each warp and weft yarn consists of four $\mathrm{Z}$ twisted filaments with 125 TPM (Twist Per Meter).

The textile was experimentally studied to get the mechanical behaviour of the yarns, extracted from the fabric, and of the glass reinforcement, as well. An overview of the experimental methods, devices and some results are presented here. 
Table I. Feature of the glass textile.

\begin{tabular}{ll}
\hline Weave & Plain weave \\
\hline Fibres & Glass EC9 \\
Filament diameter $(\mu \mathrm{m})$ & 9 \\
Ends count $($ yarns $/ \mathrm{cm})$ & Warp: $9.7 \pm 5 \%$ \\
Pick count $($ yarns $/ \mathrm{cm})$ & Weft: $9.4 \pm 5 \%$ \\
Yarn linear density $($ tex $)$ & Warp: $136 \times 4 ;$ Weft: $136 \times 4$ \\
Areal density $\left(\mathrm{g} / \mathrm{m}^{2}\right)$ & I $100 \pm 5 \%$ \\
\hline
\end{tabular}

\section{Yarn: Tensile test}

Tensile tests were carried out by an INSTRON device (load cell $500 \mathrm{~N})$ on warp and weft yarns extracted from the glass plain weave reinforcement. The clamping system consisted of epoxy reinforced plates $(3 \mathrm{~mm}$ thick). Yarns were fixed by epoxy glue (LOCTITE ${ }^{\circledR}$ EA 3430 two components epoxy adhesive) and cured at room temperature (one hour) and $40^{\circ} \mathrm{C}(3 \mathrm{~h})$. The gauge length was $150 \mathrm{~mm}$ and testing speed $5 \mathrm{~mm} / \mathrm{min}$ (ASTM D2256-15). Five tests were performed for each yarn direction.

Figure 2 details the tensile force vs. strain curves of the glass yarn, considering the free length as base length and the cross-head displacement for strain calculation. Comparison of yarn tensile test in warp and weft directions showed that the weaving process had negligible effect on tensile behaviour of yarns extracted from specimen. Besides, glass yarns depict an approximately linear tensile behaviour.

\section{Fabric: Uniaxial bias extension test}

Bias extension test is extensively adopted to characterize the shear behaviour of fabrics. 6,24 Rectangular specimen of textile are loaded such that the warp and weft directions of the yarns are orientated initially at $\pm 45^{\circ}$ to the direction of the applied tensile load. ${ }^{25}$

In the investigation, the specimen had free length/ width ratio $\lambda=H_{0} / W_{0}=2$ (Figure 3(a)) in order to guarantee a pure shear zone in the centre of the specimen (Figure 3(b), region A) ${ }^{25}$ Assuming no sliding between the warp and weft yarns during the deformation, ${ }^{24}$ the shear angle $\gamma$ can be related directly to the displacement $(d)$ of the crosshead, by the equation

$$
\gamma=\frac{\pi}{2}-2 \theta=\frac{\pi}{2}-2 \cos ^{-1}\left(\frac{D+d}{\sqrt{2} D}\right)
$$

Two pairs of aluminium tabs were glued (LOCTITE $^{\circledR}$ EA 3430 two components epoxy adhesive) on the specimen and placed in the clamps of the tensile machine. All tests were performed at room temperature and speed of $10 \mathrm{~mm} / \mathrm{min}$. During loading, a digital camera recorded images for digital image

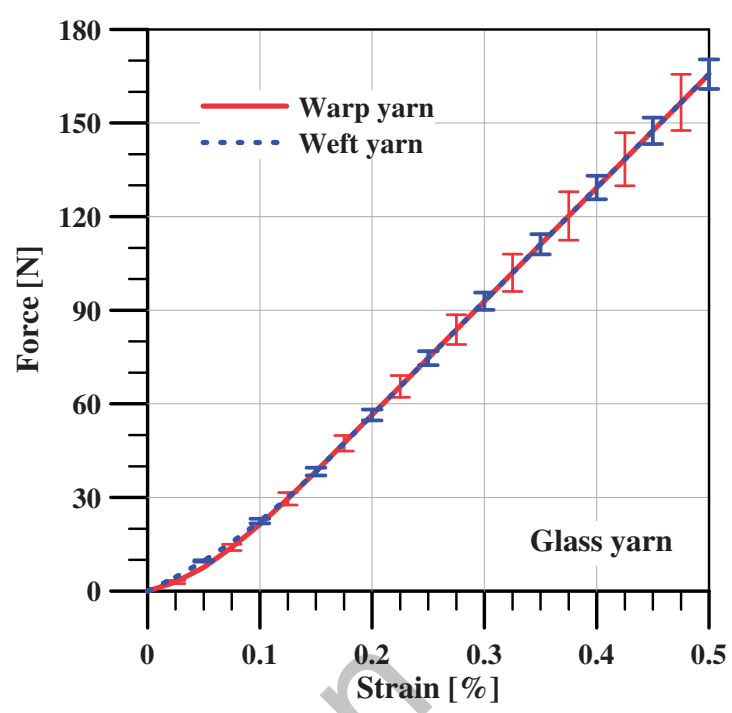

Figure 2. Tensile response of glass yarns extracted from the textile reinforcement. Average and standard deviation (error bars) of five tests.

correlation (DIC) analysis (see details in a below section). Post processing of the displacement field, measured by DIC, allowed calculation of the shear angle distribution on the reinforcement surface.

The comparison of the theoretical based on kinematic analysis (equation (1)) and the local shear angle measured by DIC in the centre of specimen showed that shear angles is in good agreement up to $\approx 25^{\circ}$ (Figure 4), and then they start to diverge. It depends on some deformation mechanisms, such as local compression and bending of the yarns, neglected in the kinematic model. The measured shear angle distribution by DIC on the complete surface $\left(200 \times 100 \mathrm{~mm}^{2}\right)$ of a bias specimen for an applied theoretical shear angle of $\approx 30^{\circ}$ is depicted in Figure 5. The assumption of the kinematic model distinction of three zones was clearly observed in the experiments (see Figure 3).

\section{Fabric: Uniaxial and biaxial tensile tests}

The uniaxial and biaxial tensile tests of the glass woven reinforcement were performed by using a home-design device equipped with 12 independent jacks along two orthogonal axes (Figure 6(b)). The jacks can slide on two rails, on each side, to allow for transversal displacements in the direction orthogonal to the load. The jacks are connected by hinges to allow selfalignment to the load direction. Each jack has a brushless motor equipped with an absolute encoder and coupled with a planetary gearbox to transform rotational into linear motion through a ball screw mounted on the axis. 

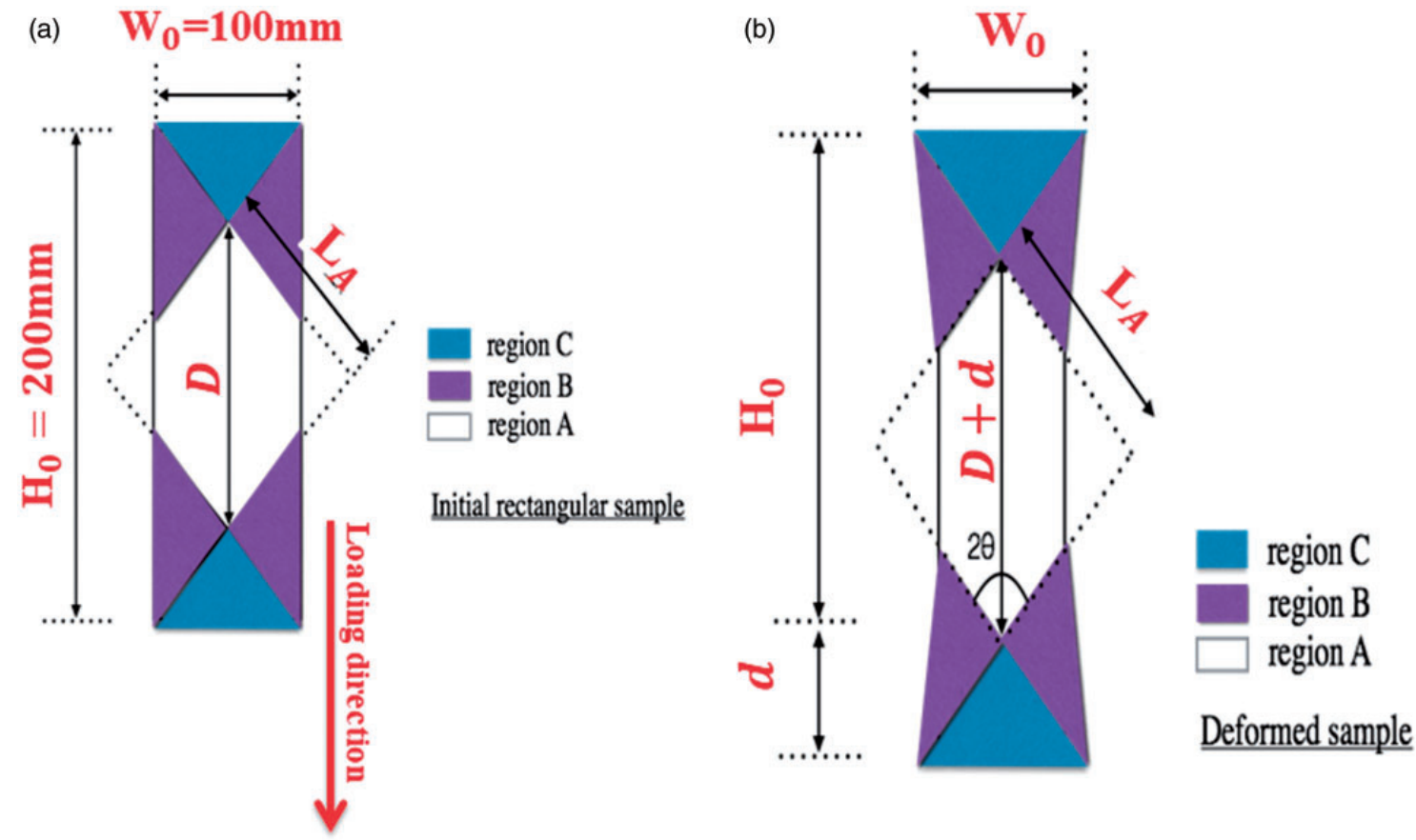

Figure 3. Scheme of the specimen for uniaxial bias extension test. In-plane shear angle distribution; (a) before shear deformation; (b) after shear deformation.

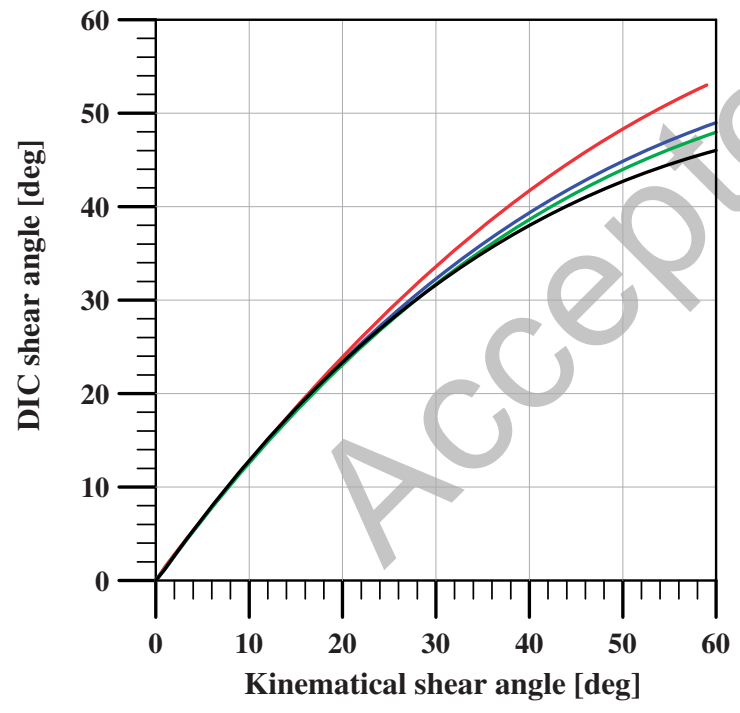

Figure 4. Comparison of measured and theoretical shear angle for bias extension tests of four specimens.

Cross-shaped specimens (Figure 6(a)) were adopted for biaxial loading. Arms of the specimens had width of $100 \mathrm{~mm}$ to create a biaxial loaded portion of $100 \times 100$ $\mathrm{mm}^{2}$. A pair of aluminium tabs were glued (LOCTITE ${ }^{\circledR}$ EA 3430 epoxy adhesive) on the clamping zone of each arm of the specimen. Strip of width and length of $100 \mathrm{~mm}$ and $400 \mathrm{~mm}$, respectively, was used

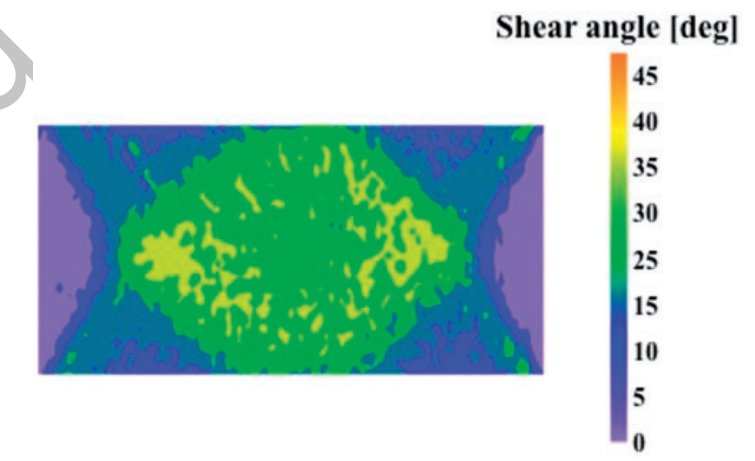

Figure 5. Contour plot of the DIC measured shear angle distribution during bias extension test for a theoretical shear angle of $\approx 30^{\circ}$.

for uniaxial tensile loading (ASTM D5034-17). All tests were conducted at room temperature. The biaxial tests were performed with different ratio $\mathrm{R}$ of the warp to the weft displacement rate (e.g. R21 means a displacement rate in warp direction double than the weft one).

As for the bias test, a digital camera recorded images of the specimen centre for measurements of the displacement field and calculation of the strain distribution by the DIC technique. To avoid the effect of the boundary on the strain measurements (e.g. corners at the intersection of arms of the cruciform specimen), the area of interest (AOI) for the DIC was a square portion 
(a)

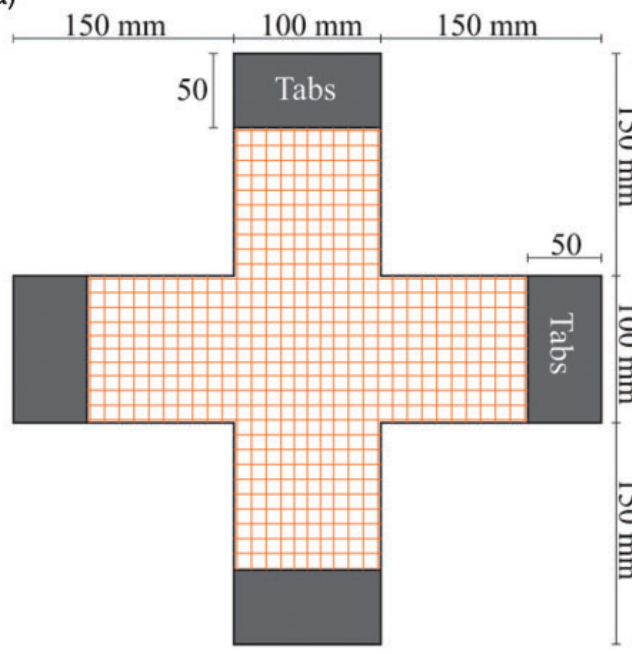

(b)

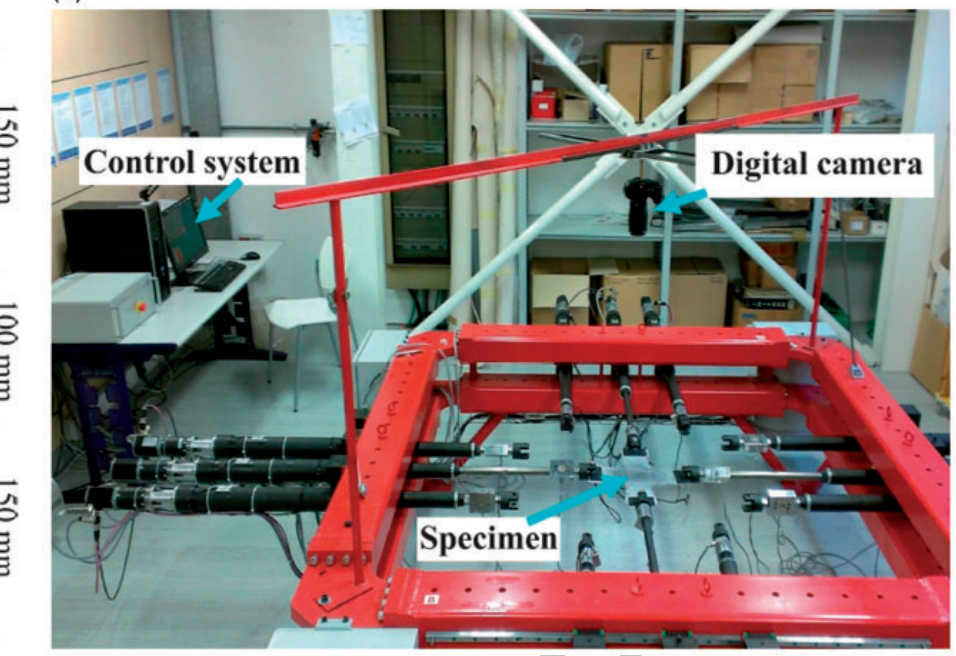

Figure 6. (a) Cross-shaped fabric specimen dimensions, (b) device for uniaxial and biaxial tensile tests.

(side $4 \mathrm{~cm}$ ) in the centre of the specimen. Results of uniaxial and biaxial tensile tests are presented and compared to the numerical predictions in the sections below.

\section{Fabric: Out-of-plane bending behaviour}

For the sake of completeness of the experimental measurements and due to the importance of the out-of-plane mechanical behaviour, bending test results are here summarized, although they are not considered for the numerical assessments. Woven textile has a unique structure and the bending properties cannot be deduced from in-plane properties such as isotropic continuous materials. ${ }^{26}$ Two standard tests, namely Kawabata test and Cantilever test, are commonly adopted to deduce the bending properties. In the present context, the cantilever test method coupled with and optical measurement was selected to measure the bending behaviour of the yarns and fabrics under their own weight (Figure 7). The cantilever setup was proposed first by Peirce. ${ }^{27}$ Assuming linear elastic relationship between the bending moment and the curvature of the strip, the bending stiffness is calculated.

Bending test procedure had two steps. First, the specimen of the selected length and width of $50 \mathrm{~mm}$ was positioned in the clamping system, with the correct alignment of the considered yarns in the bending direction (see Figure 7). Second, image of the bent under its own weight specimen was analysed to detect and measure the deformed shape.

Fitting of the bent shape of four different overhanging lengths $L$ in the range of $50-80 \mathrm{~mm}$ (coefficient of correlation $\mathrm{R}^{2}>0.97$ ) is depicted in Figure 8 . Increasing the overhanging length, the curvature in

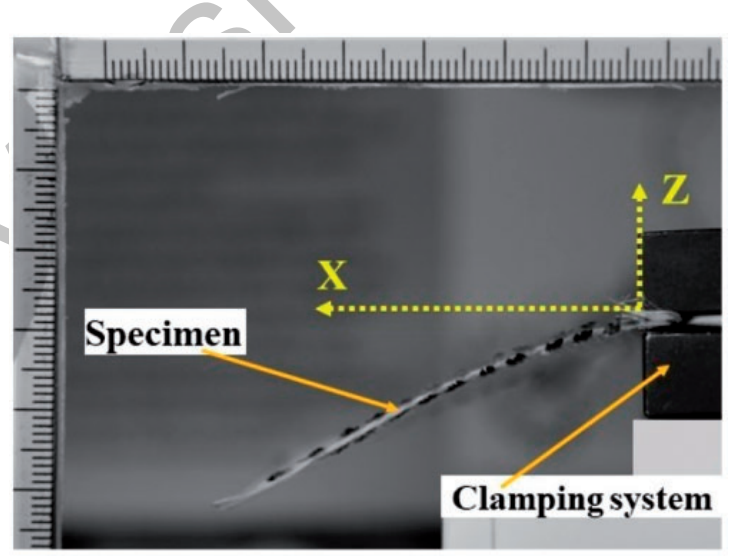

Figure 7. Bending test setup.

both warp and weft direction raised uniformly (Figure 8). The balanced fabric allowed recording of very similar shape for both warp and weft directions. The estimated bending moment and curvature of the glass textile are collected in Figure 9 for the different overhanging lengths.

\section{Details for the DIC}

The bias tests, as well as, uniaxial and biaxial tensile tests were assisted with a digital camera (Nikon D800) acquiring frames of the full specimen at a frequency of $1 \mathrm{~Hz}$ with a resolution of $7000 \times 4000$ pixels. The measurement of the full field displacement and the calculation of strain on the external surface of the specimen during loading were achieved by the DIC technique ${ }^{28}$ using the software VIC-2D. ${ }^{29}$ For this purpose, the surface of the specimen was randomly speckled with 

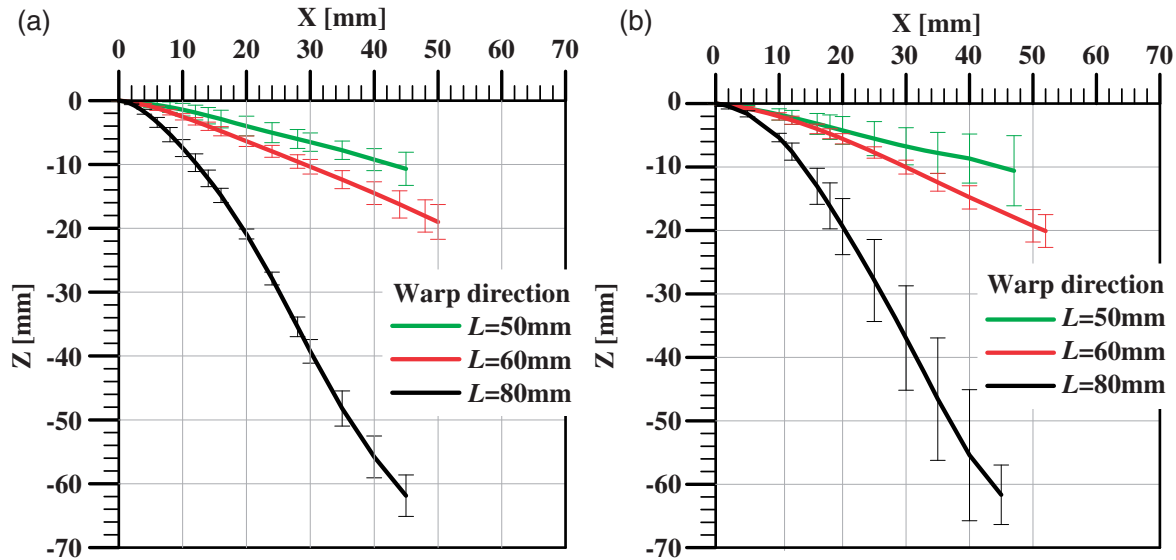

Figure 8. Sixth order polynomial fitting of bent shape with different overhanging length: (a) warp direction, (b) weft direction. Average and standard deviation (error bars) of three tests.
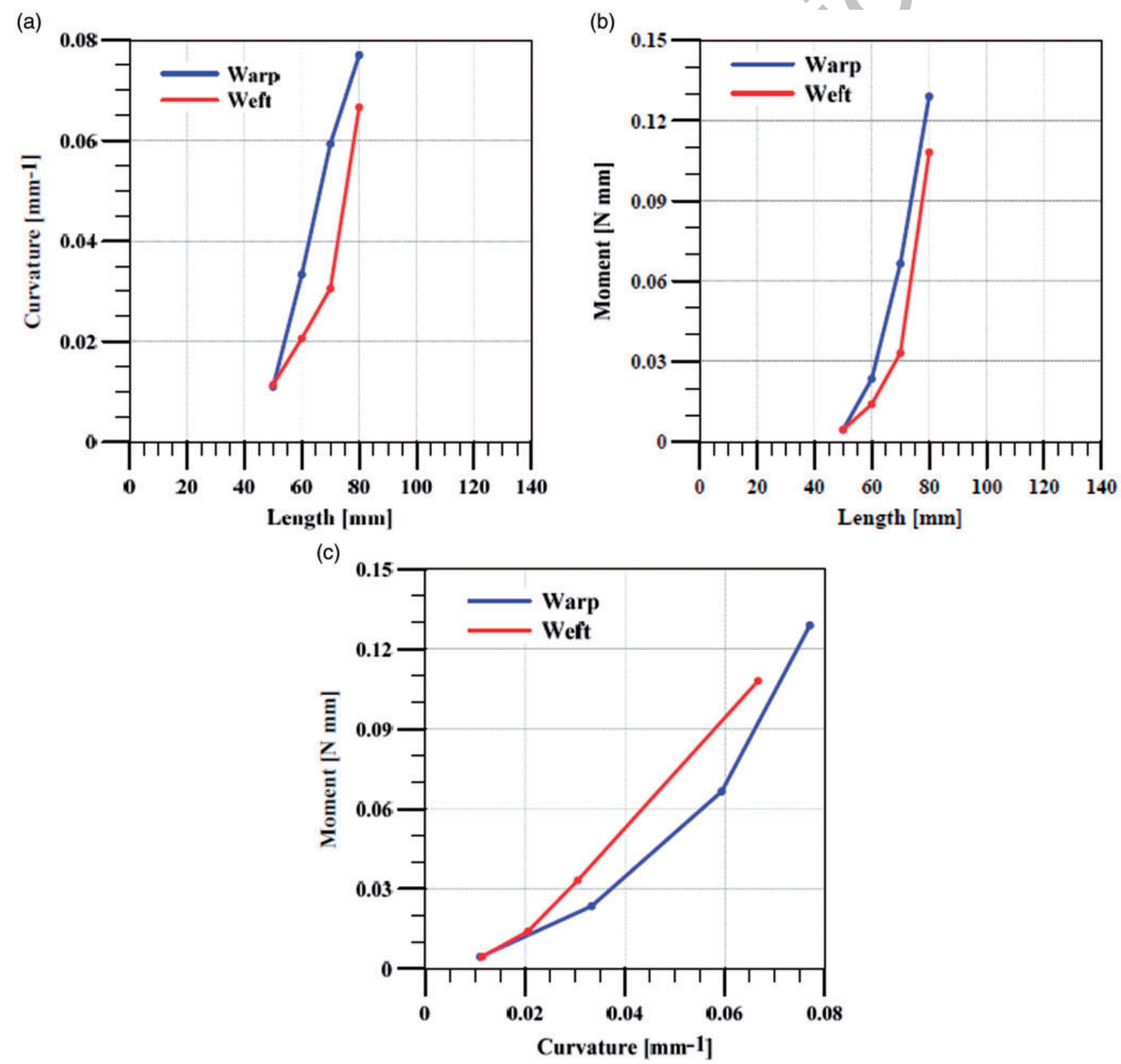

Figure 9. Bending behaviour of the glass composite reinforcement: (a) curvature vs. overhanging length; (b) bending moment vs. overhanging length; and (c) bending moment vs. curvature. 
black acrylic paints (see e.g. a patter on a specimen for bias extension test in Figure 10). Some of the adopted parameters for correlation were: subset size 40, step size 4 , filter size 15 . Those were selected assessing that lower values of subset and step sizes did not provide considerable variation of the calculated strain filed.

\section{Theoretical background of the hyperelastic constitutive model}

The yarn is an assembly of fibres oriented approximately in the same direction. The textile weaving conditions (e.g. yarns tensioning) and the interlacement considerably constrain the movement of the fibres in the yarn. Hence, the yarn can be considered as a compact, homogeneous and continuum material. The deformation of a homogeneous yarn is a combination of four modes: elongation, compaction, distortion and longitudinal shear (see Figure 11).

\section{Constitutive equation for the yarn}

The mechanical behaviour of the yarns is here modelled by a hyperelastic material model. ${ }^{30,31}$ An elastic strain energy potential per unit volume $w$ exists which only depends on the current strain state. Assuming: (i) reversible behaviour of materials, (ii) no dissipate energy, and (iii) fulfilment of Clausius-Duhem inequality, the constitutive equation of a hyperelastic material is written

$$
\underline{\underline{S}}(\underline{\underline{F}})=2 \frac{\partial w(\underline{\underline{F}})}{\partial \underline{\underline{C}}}
$$

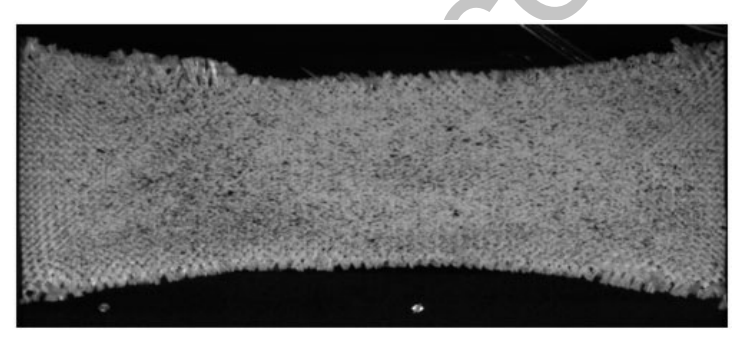

Figure I0. Speckle pattern on a specimen surface for uniaxial bias extension test.
Here $F$ is the deformation gradient tensor and $\underline{\underline{S}}$ is the second Piola-Krichhoff stress tensor. The potential energy can be written as a function of the right Cauchy-Green strain tencor $\underline{\underline{C}}$

$$
w=w(\underline{\underline{C}}) \text { with } \underline{\underline{C}}=\underline{\underline{F}}^{T} \cdot \underline{\underline{F}}
$$

The invariants of tensor $\underline{\underline{C}}$ are

$$
I_{1}=\operatorname{Tr}(\underline{\underline{C}}), I_{2}=\frac{1}{2}\left(\operatorname{Tr}(\underline{\underline{C}})^{2}-\operatorname{Tr}\left(\underline{\underline{C}}^{2}\right)\right), I_{3}=\operatorname{det} \underline{\underline{C}}
$$

The local change of volume during deformation is described by the Jacobian $J=\sqrt{I_{3}}=\operatorname{det} F$.

For a unidirectional fibrous transversally isotropic material, a unit vector $\underline{M}$ in the direction of the fibre allows the definition of a structural tensor ${ }^{32}$

$$
\underline{\underline{M}}=\underline{M} \otimes \underline{M}
$$

Then, the strain energy density function for transversal isotropic material is defined by the three invariants of $\underline{\underline{C}}$ and of the two mixed invariants, as ${ }^{33,34}$

$$
\begin{gathered}
w=w\left(I_{1}, I_{2}, I_{3}, I_{4}, I_{5}\right) \\
I_{4}=\underline{\underline{C}}: \underline{\underline{M}} \quad I_{5}=\underline{\underline{C^{2}}: \underline{\underline{M}}}
\end{gathered}
$$

\section{Strain energy function based on different deformation modes}

The strain energy potential can be defined as function of invariants directly related to the deformation modes of the yarns (Figure 11), namely: $I_{\text {elong }}$ for the elongation in the direction of the fibres, $I_{\text {comp }}$ for the transverse compaction, $I_{\text {dist }}$ for the distortion (change of angle) in the transverse section and $I_{s h}$ for the shear along the fibre direction. These physically based
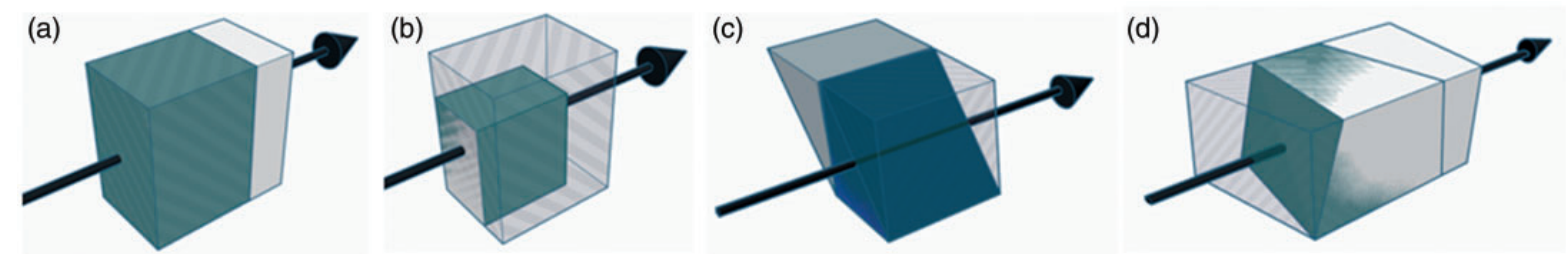

Figure I I Four different deformation modes of the yarn: (a) elongation, (b) compaction of the cross section, (c) distortion of the cross section and (d) longitudinal shear. 
invariants are function of the invariants defined in equations (4) and (7)

$$
\begin{aligned}
& I_{\text {elong }}=\frac{1}{2} \ln \left(I_{4}\right), \quad I_{\text {comp }}=\frac{1}{4} \ln \left(\frac{I_{3}}{I_{4}}\right), \\
& I_{\text {dist }}=\frac{1}{2} \ln \left(\frac{I_{1} I_{4}-I_{5}}{2 \sqrt{I_{3} I_{4}}}+\sqrt{\left(\frac{I_{1} I_{4}-I_{5}}{2 \sqrt{I_{3} I_{4}}}\right)^{2}-1}\right), \\
& I_{s h}=\sqrt{\frac{I_{5}}{I_{4}^{2}}-1}
\end{aligned}
$$

Elongation strain energy. The strain energy functions corresponding to the linear $\left(I_{\text {elong }} \leq I_{\text {elong }}^{0}\right)$ and non-linear $\left(I_{\text {elong }}>I_{\text {elong }}^{0}\right.$ ) parts of the elongation behaviour of the yarn are

$$
\begin{aligned}
w_{\text {elong }}^{\text {lin }}= & \frac{K_{\text {elong }}-K_{\text {elong }}^{0}}{6 S_{0}}\left(I_{\text {elong }}^{0}\right)^{2} \\
& -\frac{K_{\text {elong }}-K_{\text {elong }}^{0}}{2 S_{0}}\left(I_{\text {elong }}^{0} I_{\text {elong }}\right)+\frac{K_{\text {elong }}}{2 S_{0}}\left(I_{\text {elong }}^{2}\right) \\
w_{\text {elong }}^{n l} & =\frac{K_{\text {elong }}^{0}}{2 S_{0}}\left(I_{\text {elong }}^{2}\right)+\frac{K_{\text {elong }}-K_{\text {elong }}^{0}}{6 S_{0} I_{\text {elong }}^{0}}\left(I_{\text {elong }}^{3}\right)
\end{aligned}
$$

Distortion strain energy. The numerical modelling considers constant distortion stiffness, which leads to the following strain energy function

$$
w_{\text {dist }}=\frac{1}{2} K_{\text {dist }} I_{\text {dist }}^{2}
$$

The second Piola-Kirchhoff stress tensor associated to the distortion strain energy is then

$$
\begin{aligned}
& \underline{\underline{S}}_{\text {dist }}=2 K_{\text {dist }} I_{\text {dist }}
\end{aligned}
$$

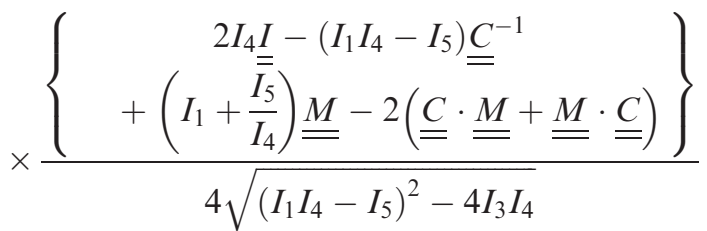

The parameter $K_{\text {dist }}$ is identified considering an equibiaxial tensile test, as for the compaction parameters.

Longitudinal shear strain energy. A linear elastic behaviour is assumed for the longitudinal shear deformation mode. Hence, the strain energy potential is

$$
w_{s h}=\frac{1}{2} K_{s h} I_{s h}^{2}
$$

The second Piola-Krichhoff tensor becomes

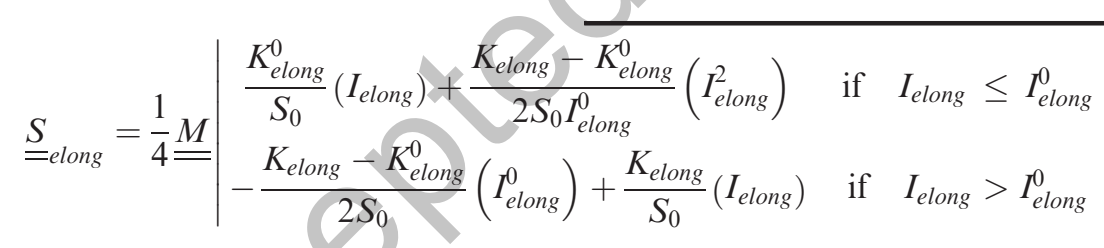

The parameters $I_{\text {elong }}^{0}, K_{\text {elong }}^{0}, K_{\text {elong }}$ are here identified assuming results of tensile test of yarns.

Compaction strain energy. A power-based strain energy function was proposed ${ }^{23}$

$$
w_{\text {comp }}=\mid \begin{array}{lll}
K_{\text {comp }}\left|I_{\text {comp }}\right|^{p} & \text { if } & I_{\text {comp }} \leq 0 \\
0 & \text { if } & I_{\text {comp }}>0
\end{array}
$$

Assuming no energy for yarn section expansion, the second Piola-Kirchhoff stress tensor is:

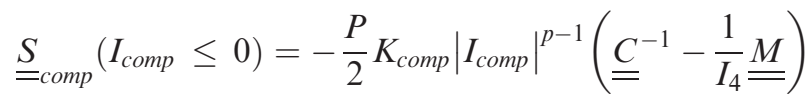

The parameters $K_{\text {comp }}$ and $p$ are identified considering an equi-biaxial tensile test of the woven fabric.
The second Piola-Kirchhoff stress tensor is

$$
\underline{\underline{S}}_{s h}=\frac{1}{2} K_{s h}\left[\frac{1}{I_{4}^{2}}(\underline{\underline{C}} \cdot \underline{\underline{M}}+\underline{\underline{M}} \cdot \underline{\underline{C}})-\frac{2 I_{5}}{I_{4}^{3}} \underline{\underline{M}}\right]
$$

The parameter $K_{s h}$ is identified by a uniaxial tensile test of the woven fabric whose elongation parameters have been previously determined.

\section{Combination of all deformation modes}

Each contribution of deformation mode is considered as independent from the other

$$
\begin{aligned}
\underline{\underline{S}} & =2\left(\frac{\partial w_{\text {elong }}}{\partial I_{\text {elong }}} \frac{\partial I_{\text {elong }}}{\partial \underline{\underline{C}}}+\frac{\partial w_{\text {comp }}}{\partial I_{\text {comp }}} \frac{\partial I_{\text {comp }}}{\partial \underline{\underline{C}}}+\frac{\partial w_{\text {dist }}}{\partial I_{\text {dist }}} \frac{\partial I_{\text {dist }}}{\partial \underline{\underline{C}}}+\frac{\partial w_{\text {sh }}}{\partial I_{\text {sh }}} \frac{\partial I_{\text {sh }}}{\partial \underline{\underline{C}}}\right) \\
& =\underline{\text { elong }}_{\underline{\text { elomp }}_{\text {comp }}}+\underline{\underline{S}}_{\text {dist }}+\underline{\underline{S}}_{\text {sh }}
\end{aligned}
$$




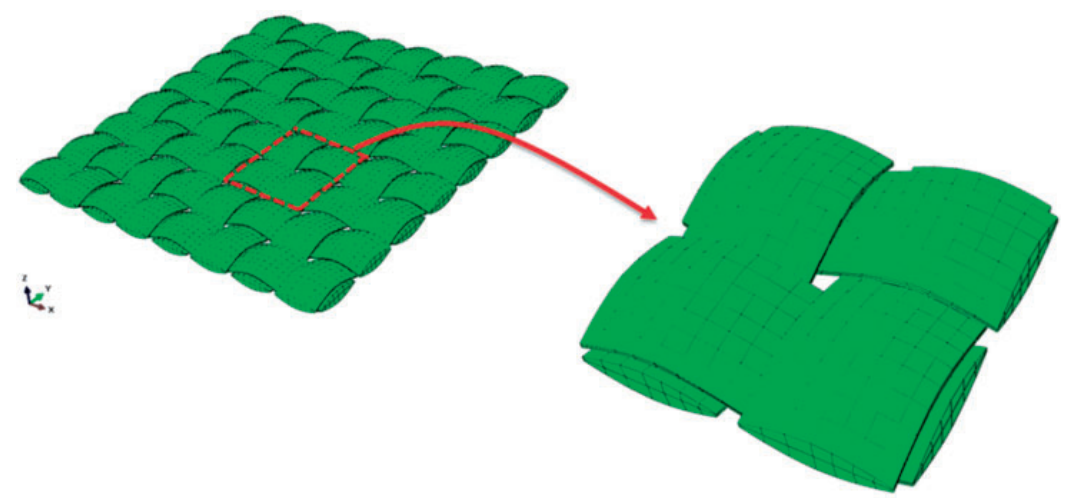

Figure 12. Representative volume of the glass plain weave composite reinforcement.

The hyperelastic constitutive model was implemented in a user material subroutine VUMAT for the FE code ABAQUS/Explicit. ${ }^{35}$

\section{Features of the FE model}

The FE discretization of the representative volume of the glass plain weave composite reinforcement adopted eight nodes hexahedral elements (C3D8).

Periodic boundary conditions, based on Carvelli et al., ${ }^{36,37}$ were adopted to simulate the realistic repetitive nature of the RVE (see Figure 12). To reproduce the $3 \mathrm{D}$ geometry of the plain weave textile, some textile samples were embedded in a transparent resin and a set of geometric features were measured by an optical microscope, namely: yarn cross-section, length, width and thickness of the unit cell. Average measurements are listed in Table 2. Those observations allowed to create the 3D solid model of the RVE assuming: lenticular cross-section of the yarns with the measured section surface, and constant cross-section along the yarn path. Besides, the contact of the yarns in the dry textile was set by a model implemented in ABAQUS/ Explicit. ${ }^{35}$ The model considers a surface-based hardcontact between the surfaces in normal direction and a frictional contact in the tangential ones, assuming the friction coefficient as 0.18 , similar to the measurements on $0^{\circ} / 90^{\circ}$ glass yarns detailed in Montero et al. ${ }^{38}$

The proper material orientations of the yarn were enforced in the numerical model by a local coordinate system encompassing in each element the local direction of the tangent to the direction of the fibres (Figure 13).

\section{Parameters identification}

For each deformation mode (see Figure 11), a strain energy density function was defined based on the experimental behaviour of the glass plain weave composite
Table 2. Size of the plain weave textile unit cells (in $\mathrm{mm}$ ).

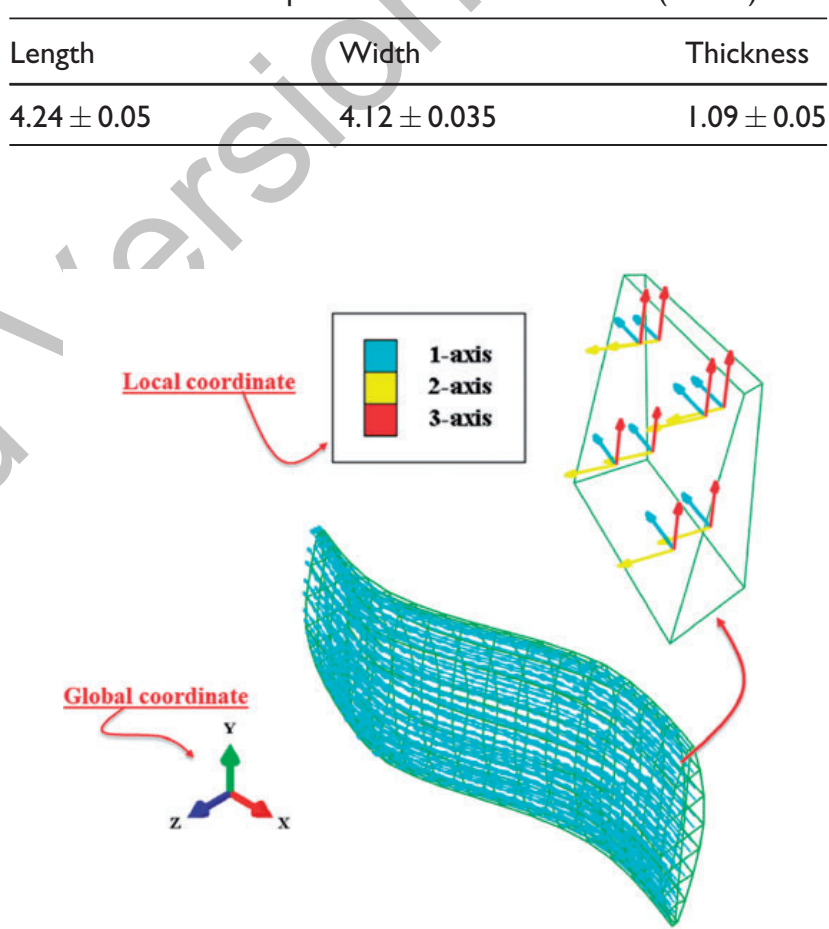

Figure 13. Local coordinate system for the yarn material orientations.

reinforcement. Afterwards, the strain energy density was considered to determine the parameters of the constitutive model.

Tensile tests of yarns, extracted from the textile after the weaving process, were considered to get realistic mechanical behaviour. The initial section of the yarn, $S_{0}$, was measured by optical microscope, while $I_{\text {elong }}^{0}$, $K_{\text {elong }}^{0}$ and $K_{\text {elong }}$ were identified by means of the sum of differences squared algorithm (see Figure 14).

The parameters $K_{\text {comp }}, K_{\text {dist }}$ and $p$ were identified by an inverse analysis based on equi-biaxial tension test 


\begin{tabular}{ll}
\hline $\begin{array}{l}\text { Identification parameters for } \\
\text { yarn elongation }\end{array}$ \\
\hline$S_{0}\left(\mathrm{~mm}^{2}\right)$ & 0.695 \\
$I_{\text {elong }}^{0}$ & 0.001336 \\
$K_{\text {elong }}^{0}(N)$ & 11660 \\
$K_{\text {elong }}(N)$ & 36714 \\
\hline
\end{tabular}

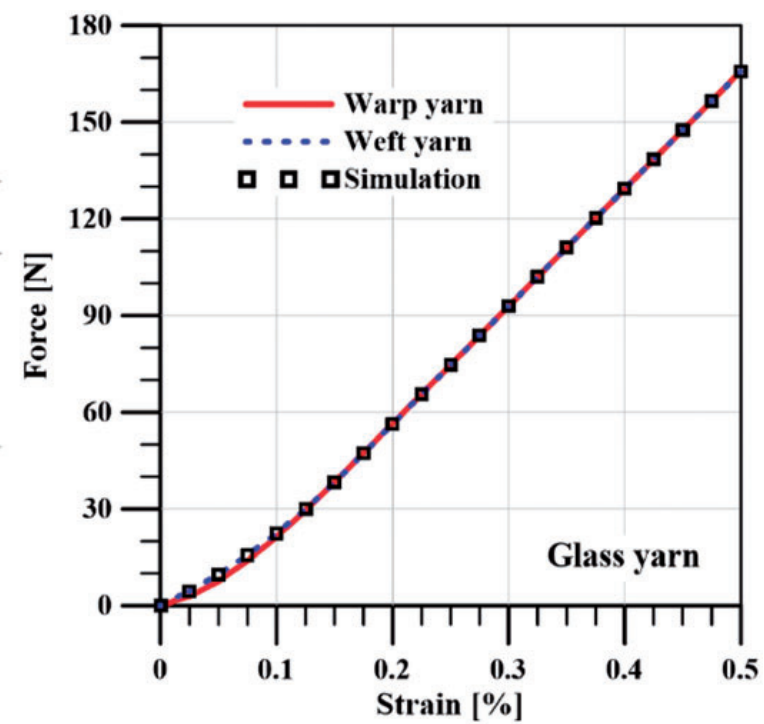

Figure 14. Identification of the yarns elongation parameters.
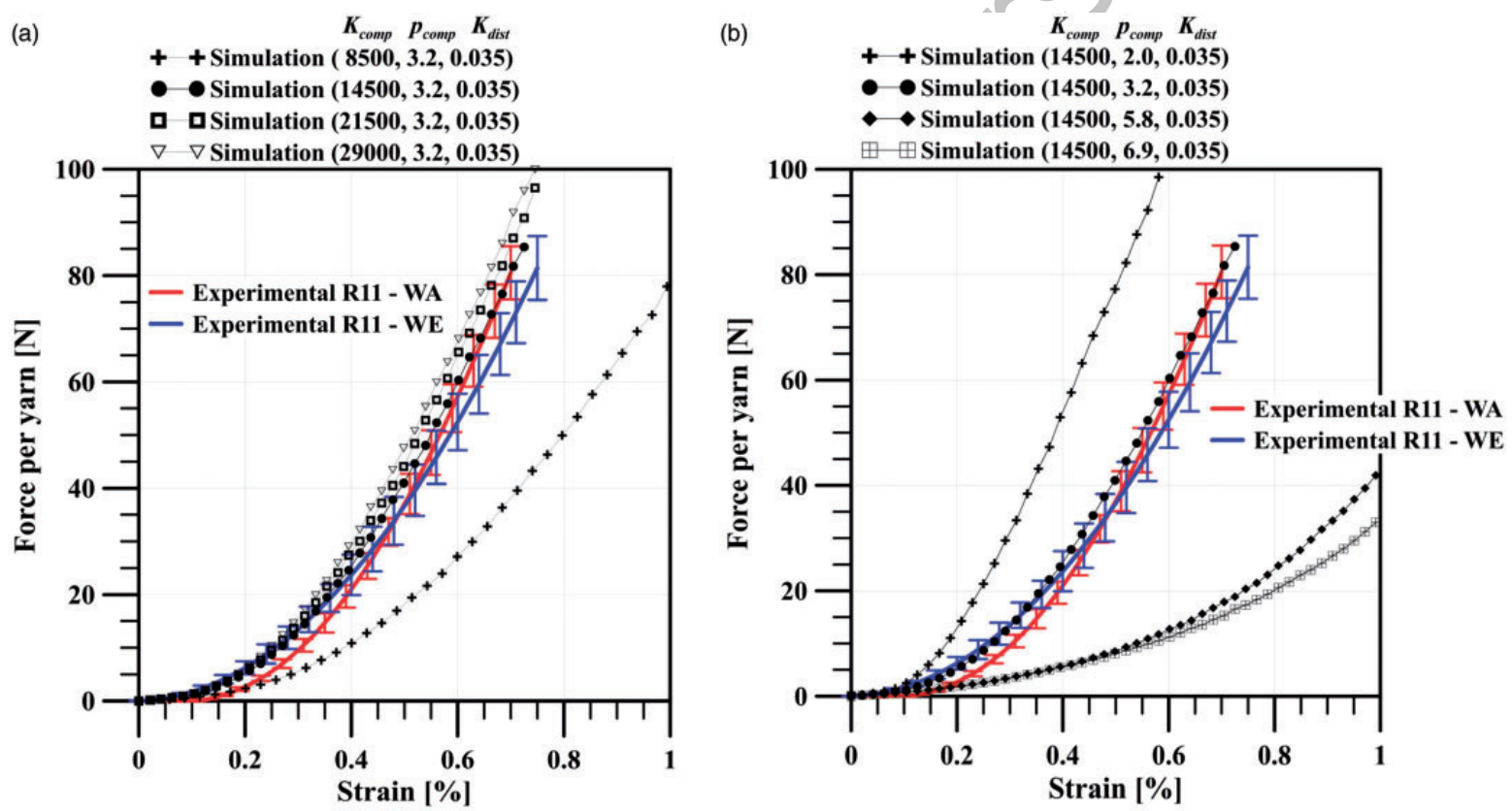

Figure I5. Identification of the parameters of compaction and distortion using biaxial RII tension test. Effect of parameter (a) $K_{\text {comp }}$ and (b) Pcomp.

(R11) of the glass textile. The inverse analysis allowed having the equi-biaxial response very close to the measured one, with few iterations (see Figure 15). Figure 15 (a) and (b) illustrates the sensitivity of $K_{\text {comp }}$ and $p_{\text {comp }}$. It shows that the stiffness increased when increasing $K_{\text {comp }}$, while increasing $p_{\text {comp }}$ the tensile stiffness of glass fabric decreased significantly. The adopted identified parameters $K_{\text {comp }}, K_{\text {dist }}$ and $p_{\text {comp }}$ are $14500 \mathrm{~N}$, $0.035 \mathrm{MPa}$ and 3.2, respectively.
Nevertheless, the existence of local minima of the error estimation highlights that the initial parameters must be close to the final solution to have convergence. An initial trial and error approach before starting the identification procedure allowed having the proper initial values (Figure 15).

The main deformation modes of a fabric under tensile loading are the yarn elongation and longitudinal shear. Hence, the parameter of equation (17) was set 


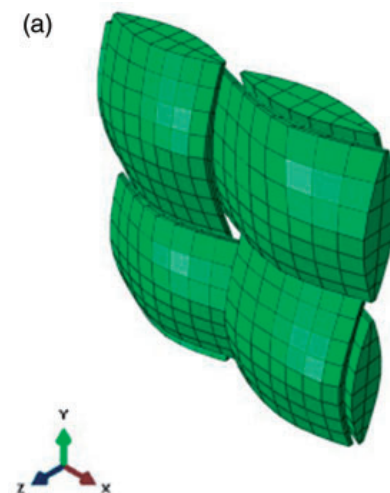

Mesh 1:

Number of elements $=840$

Number of nodes $=1536$

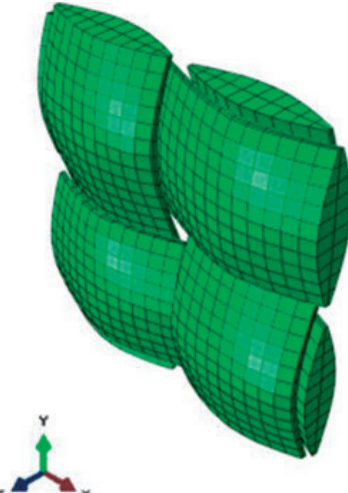

Mesh 2:

Number of elements $=1840$

Number of nodes $=3168$

(b)

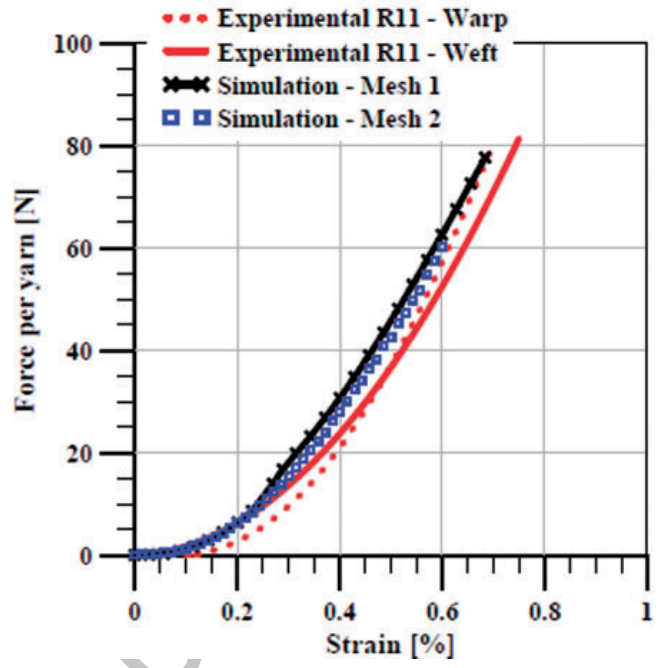

Figure I6. Effect of the refinement of mesh for loading ratio RII; (a) two unit cell with different number of elements, (b) comparison of the force per yarn vs. strain.
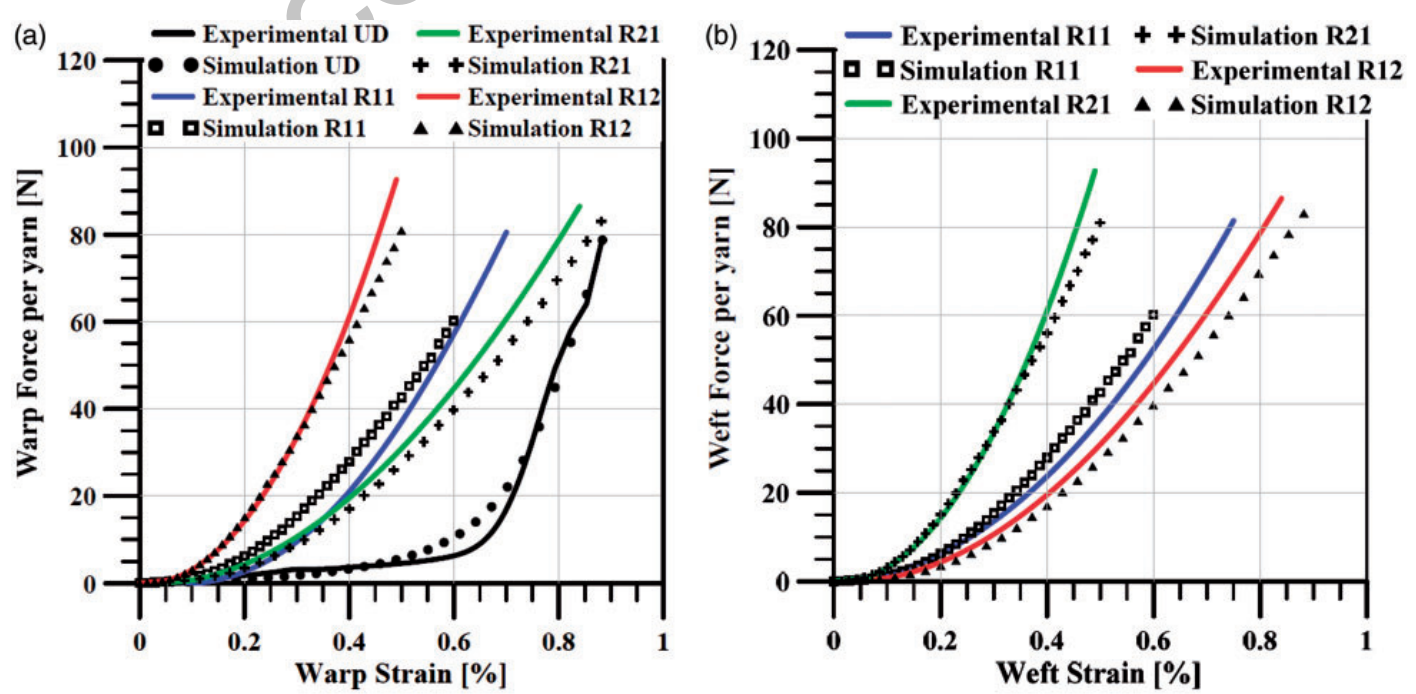

Figure 17. Comparison of simulation and experimental results for biaxial tensile loading with different displacement ratio R: (a) warp direction; (b) weft direction. 

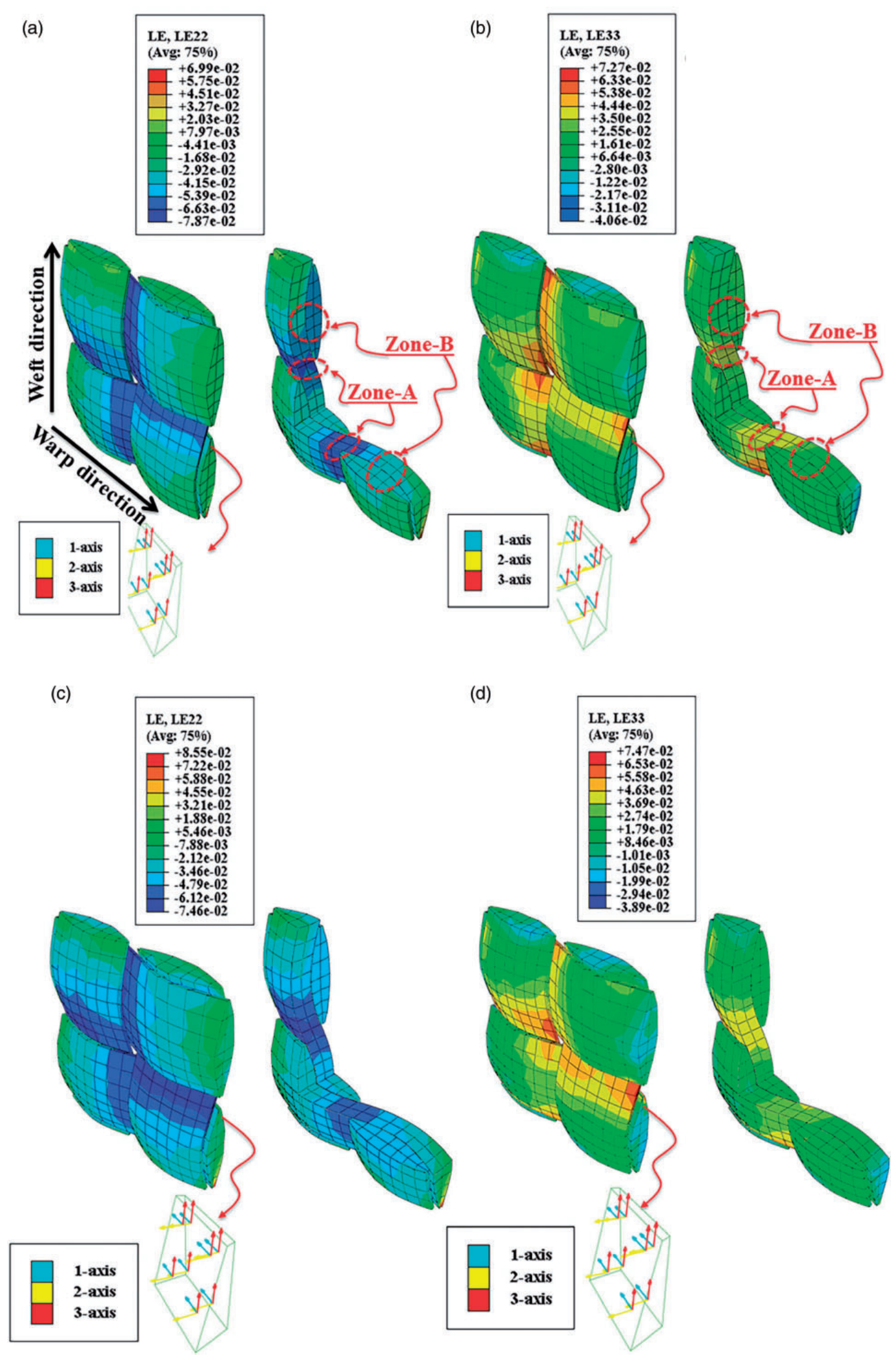

Figure I8. Map of logarithmic strain components distribution for: biaxial tensile loading RII at ION per yarn in both direction (a) $L E_{22}$ and (b) $L E_{33}$; biaxial tensile loading $R 2 I$ at $I 0 \mathrm{~N}$ yarn in warp and $8 \mathrm{~N}$ per yarn in weft direction (c) $L E_{22}$ and (d) $L E_{33}$. 


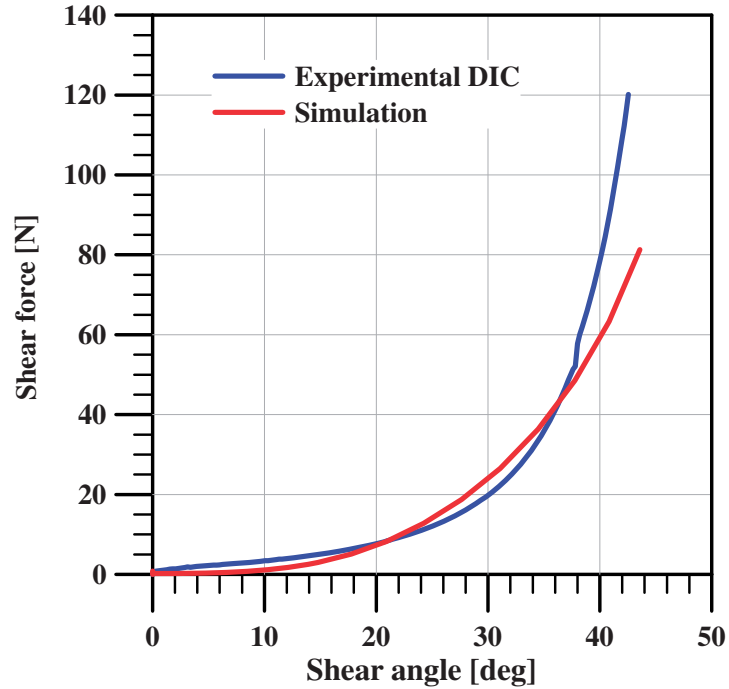

Figure 19. Comparison of simulation and experimental results for in-plane shear loading.

once the parameters of the elongation were determined. This is justified being the strain energies associated to the elongation and longitudinal shear much greater than the compaction and distortion. The $K_{s h}$ was estimated for in-plane shear deformation mode, and the adopted value was $3 \mathrm{MPa}$.

\section{Results and comparisons}

The hyperelastic constitutive model was adopted to numerically predict the mechanical behaviour of the glass plain weave composite reinforcement with uniaxial, biaxial and in-plane shear loadings. Preliminary analyses were conducted for mesh sensitivity and to select the proper mesh for all results presented hereafter.

\section{Mesh sensitivity}

An initial mesh sensitivity analysis allowed selecting the proper discretization for further numerical predictions. Two meshes were adopted with element size of about $0.3 \mathrm{~mm}$ and $0.2 \mathrm{~mm}$, respectively. Considering biaxial tensile loading with ratio $\mathrm{R} 11$, the predictions for both meshes are shown in Figure 16. The very similar results allowed selecting the mesh with lower number of elements for simulation of the all considered loading conditions.

\section{Bi-axial tensile and in-plain shear loadings}

During tensile loading, the undulated yarns in the plain weave textile tend to become straight. The yarn crimp or waviness within the textile is the main reason for the initial non-linear macroscopic load-strain response.
Once the yarns are straightened, the response changes into a steep linear behaviour. The tensile behaviour in one yarn direction is affected by the tensile load imposed in the other yarn direction and vice versa. This biaxial tensile coupling was properly simulated by the present numerical model.

Comparison of experimental measurements and numerical results of bi-axial tensile loading with different displacement ratio $\mathrm{R}$ is detailed in Figure 17. The good agreement between the experimental measurements and numerical predictions for all loading ratios (R11, R12 and R21) highlights the accuracy of the mechanical simulations based on a hyperelastic constitutive material model. The balanced glass plain weave composite reinforcement allowed simulation of the uniaxial tensile loading only in warp direction. The model correctly predicts the nonlinear initial behaviour (see Figure 17(a)), as observed experimentally.

An insight of the local behaviour of the textile is only possible by the numerical model. The predicted distributions of the logarithmic strain components, in the local reference frame of the yarns, are shown in Figure 18 for biaxial tensile loading with ratio R11 and R21. They show the main concentration at the contact between warp and weft yarns (zone-B) and at the gap area between yarns (zone-A).

The drawbacks of the theoretical kinematic model have been avoided by the numerical model, which predict a shear behaviour in agreement to the experimental measurements for shear angles higher than $35^{\circ}$ (see Figure 19). This is due to the complete set of deformation modes considered in the numerical model including the shear and compressive behaviour of the yarns.

\section{Conclusions}

The comparison of meso-scale numerical model predictions and experimental results for in-plane deformations of a glass plain weave composite reinforcement was presented. The numerical analyses of the representative volume were performed assuming a hyperelastic constitutive model for the yarn material. Simulation was dedicated to the mechanical response of the dry textile with different loading conditions: uniaxial tensile, biaxial tensile with different displacement ratio in the warp and weft directions, and bias extension for the shear behaviour. The numerical results had good agreement with experimental measurements for a large strain range, above any level for real forming processes.

The accuracy of the model in predicting the macro response as well as the local distribution of stress and strain inside the yarns provides a powerful tool to investigate the mechanical behaviour and to design such reinforcement for composite materials considering the variation of the wide range of parameters before the 
weaving manufacturing, e.g. warp and weft spacing, and yarn material once the parameter of the constitutive model has been identified.

\section{Declaration of conflicting interests}

The author(s) declared no potential conflicts of interest with respect to the research, authorship, and/or publication of this article.

\section{Funding}

The author(s) disclosed receipt of the following financial support for the research, authorship, and/or publication of this article: The work was supported by the Italian Ministry of Economic Development under the research project 'Tetraxial' (GrantNo.MI01_00202).

\section{References}

1. Joffre T, Miettinen A, Berthold F, et al. X-ray micro-computed tomography investigation of fibre length degradation during the processing steps of shortfibre composites. Compos Sci Technol 2014; 105: 127-133.

2. Lomov SV, Ivanov DS, Verpoest I, et al. Meso-FE modelling of textile composites: road map, data flow and algorithms. Compos Sci Technol 2007; 67: 1870-1891.

3. Ruggy KL and Cox BN. Deformation mechanisms of dry textile preforms under mixed compressive and shear loading. J Reinf Plast Compos 2004; 23: 1425-1442.

4. Archer E, Buchanan S, McIlhagger AT, et al. The effect of $3 \mathrm{D}$ weaving and consolidation on carbon fiber tows, fabrics, and composites. J Reinf Plast Compos 2010; 29: $3162-3170$.

5. Boisse P, Zouari B and Daniel JL. Importance of in-plane shear rigidity in finite element analyses of woven fabric composite preforming. Compos Part A 2006; 37: 2201-2212.

6. Boisse P, Hamila N, Guzman-Maldonado E, et al. The bias-extension test for the analysis of in-plane shear properties of textile composite reinforcements and prepregs: a review. Int J Mater Form 2017; 10: 473-492.

7. Hamila N, Boisse P and Chatel S. Semi-discrete shell finite elements for textile composite forming simulation. Int J Mater Form 2009; 2: 169-172.

8. Yu WR, Harrison P and Long A. Finite element forming simulation for non-crimp fabrics using a non-orthogonal constitutive equation. Compos Part A 2005; 36: 1079-1093.

9. Zouari B, Daniel JL and Boisse P. A woven reinforcement forming simulation method. Influence of the shear stiffness. Comput Struct 2006; 84: 351-363.

10. Harrison P, Abdiwi F, Guo Z, et al. Characterising the shear-tension coupling and wrinkling behaviour of woven engineering fabrics. Compos Part A 2012; 43: 903-914.
11. Lomov SV and Verpoest I. Model of shear of woven fabric and parametric description of shear resistance of glass woven reinforcements. Compos Sci Technol 2006; 66: 919-933.

12. Lindberg J, Behre B and Dahlberg B. Mechanical properties of textile fabrics, part III: shearing and buckling of various commercial fabrics. Text Res J 1961; 31: 99-122.

13. Grosberg P and Park BJ. The mechanical properties of woven fabrics: part V: the initial modulus and the frictional restraint in shearing of plain weave fabrics. Text Res $J$ 1966; 36: 420-431.

14. Grosberg P, Leaf GAV and Park BJ. The mechanical properties of woven fabrics part VI: the elastic shear modulus of plain-weave fabrics. Text Res J 1968; 38: 1085-1100.

15. Spivak SM and Treloar LRG. The behavior of fabrics in shear: part III: the relation between bias extension and simple shear. Text Res J 1968; 38: 963-971.

16. Wang J, Page JR and Paton R. Experimental investigation of the draping properties of reinforcement fabrics. Compos Sci Technol 1998; 58: 229-237.

17. Alsayednoor J, Lennard F, Yu WR, et al. Influence of specimen pre-shear and wrinkling on the accuracy of uniaxial bias extension test results. Compos Part A 2017; 101: 81-97.

18. Syerko E, Comas-Cardona S and Binetruy C. Models for shear properties/behavior of dry fibrous materials at various scales: a review. Int J Mater Form 2015; 8: 1-23.

19. Haanappel SP, Ten Thije RHW, Sachs U, et al. Formability analyses of uni-directional and textile reinforced thermoplastics. Compos Part A 2014; 56: 80-92.

20. Ji F, Li R and Qiu Y. Simulate the dynamic draping behavior of woven and knitted fabrics. $J$ Ind Text 2006; 35: 201-215.

21. Boisse P, Hamila N, Vidal-Sallé E, et al. Simulation of wrinkling during textile composite reinforcement forming. Influence of tensile, in-plane shear and bending stiffnesses. Compos Sci Technol 2011; 71: 683-692.

22. Smith JR, Vaidya UK and Johnstone JK. Analytical modeling of deformed plain woven thermoplastic composites. Int J Mater Form 2014; 7: 379-393.

23. Charmetant A, Vidal-Sallé E and Boisse P. Hyperelastic modelling for mesoscopic analyses of composite reinforcements. Compos Sci Technol 2011; 71: 1623-1631.

24. Cao J, Akkerman R, Boisse P, et al. Characterization of mechanical behaviour of woven fabrics: experimental methods and benchmark results. Compos Part A 2008; 39: 1037-1053.

25. Carvelli V, Pazmino J, Lomov SV, et al. Deformability of a non-crimp 3D orthogonal weave E-glass composite reinforcement. Compos Sci Technol 2012; 73: 9-18.

26. Clapp TG, Peng H, Ghosh TK, et al. Indirect measurement of the moment-curvature relationship for fabrics. Text Res J 1990; 60: 525-533.

27. Peirce FT. The handle of cloth as a measurable quantity. J Text Inst Transac 1930; 21: 377-416. 
28. Sutton MA, Orteu JJ and Shreir HW. Image correlation for shape, motion and deformation measurements: basic concepts, theory and applications. New York: Springer Science, 2009.

29. VIC-2D, Correlated Solutions, Inc., Irmo, SC, USA, www.correlatedsolutions.com (2012, accessed 24 November 2018.

30. Ciarlet PG. Mathematical elasticity volume I: threedimensional elasticity. 1988. North Holland, Amsterdam: Elsevier.

31. Marsden JE and Hughes TJR. Mathematical foundations of elasticity. New York: Dover Publications Inc., 1983.

32. Boehler JP. Lois de comportement anisotrope des milieux continus. J Mècaniq 1978; 17: 153-190.

33. Itskov M. On the theory of fourth-order tensors and their applications in computational mechanics. Comput Meth Appl Mech Eng 2000; 189: 419-438.
34. Quanshui Z and Boehler J. Tensor function representations as applied to formulating constitutive laws for clinotropic materials. Acta Mech Sinica 1994; 10: 336-348.

35. Abaqus 6.14. User manual. Provid. RI, USA: Dassault Systèmes Simulia Corp., 2014.

36. Carvelli V and Poggi C. A homogenization procedure for the numerical analysis of woven fabric composites. Compos Part A 2001; 32: 1425-1432.

37. Carvelli V, Corazza C and Poggi C. Mechanical modelling of monofilament technical textiles. Comput Mater Sci 2008; 42: 679-691.

38. Montero L, Allaoui S and Hivet G. Characterisation of the mesoscopic and macroscopic friction behaviours of glass plain weave reinforcement. Compos Part A 2017; 95: $257-266$. 